\title{
ЭТНИЧЕСКИ СМЕШАННЫЕ БРАКИ СКВОЗЬ ПРИЗМУ ФЕНОМЕНА УДОВЛЕТВОРЕННОСТИ СУПРУЖЕСТВОМ
}

\author{
Анна Ивановна Тащёва \\ кандидат психологических наук, доцент \\ Южный федеральный университет \\ 2. Ростов-на-Дону, Россия \\ E-mail:annaivta@mail.ru \\ Светлана Валерьевна Гриднева \\ кандидат психологических наук, доцент \\ Южный федеральный университет \\ 2. Ростов-на-Дону, Россия \\ E-mail: gridneva-sveta@mail.ru

\section{Татьяна Гавриловна Стефаненко} \\ доктор психологических наук, профессор \\ Московский государственный университет имени М. В. Ломоносова \\ 2. Москва, Россия \\ E-mail: tstef@yandex.ru \\ Ольга Алексеевна Тихомандрицкая \\ кандидат психологических наук, доцент \\ Московский государственный университет имени М. В. Ломоносова \\ 2. Москва, Россия \\ E-mail: otihomandr@mail.ru
}

В статье описывается эмпирически выявленное своеобразие феномена удовлетворенности супружеством в бинациональных и однонациональных официальных супружеских парах применительно к основным его характеристикам: личная, взаимная, средняя на супружескую пару и по сферам супружества (хозяйственно-бытовая, сексуально-эротическая, досуговая, психотерапевтическая, рождение и воспитание детей, единодушие во взглядах и оценке родственников, друзей), особенности конфликтов в дву- и однонациональных браках.

Методы данного исследования: анализ литературы по изучаемой проблеме, психодиагностический метод, метод сравнения групп, методы качественно-количественного и статистического анализа результатов. 
Методический инструментарий был представлен тестом «Удовлетворенность браком» О. О. Ерёмичевой и Л. Я. Гозмана, в адаптации А. И. Тащёвой, и анкетой А. И. Тащёвой, выявляющей основные сочиально-демографические, социально-экономические и иные 19 характеристик супружеских пар.

Эмпирический объект исследования-партнеры 30 официальных супружеских пар, каждому из которых 25-35 лет (русские, армяне, осетины, украинцы, белорусы, грузины).

В челом, полученные результаты приводят к важному выводу о том, что для супругов однонациональных пар, по сравнению с бинациональными, характерны статистически достоверные более высокая удовлетворенность браком в целом; и применительно к каждой из срер супружества (хозяйственнобытовая, сексуально-эротическая, досуговая, психотерапевтическая, рождение и воспитание детей, единодушие во взглядах и оченке родственников, друзей).

Практическая значимость данного исследования заключается в возможности применения результатов в психологических центрах при работе с вступающими в брак и с разводящимися парами разного этнического состава для первичной диагностики качества взаимоотношений в браке, профилактики и психологической коррекции деструктивных супружеских конфликтов в них для оптимизачии качества супружеских отношений как одного из базовых средств продуктивной реализации государственной позитивной демографической политики.

Данная статья является фрагментом более широкого исследования на тему «Супружеские конфрликты в биэтнических парах в возрасте ранней зрелости» [7].

Ключевые слова: брак, супружество, двуэтнические браки, одноначиональные браки, качество супружества, критерии брака, удовлетворенность супружеством, стабильность брака, расширенная семья, конфликты.

Для цитирования: Тащёва А. И., Гриднева С. В., Стефаненко Т. Г., Тихомандрицкая О. А. Этнически смешанные браки сквозь призму феномена удовлетворенности супружеством // Российский психологический журнал. 2016. - T. 13. - № 3. - С. 39-52.

\title{
ETHNICALLY MIXED MARRIAGES THROUGH THE PHENOMENON OF MARRIAGE SATISFACTION
}

\author{
Anna Ivanovna Tashcheva \\ Candidate of Psychology, Associate Professor \\ Southern Federal University \\ Rostov-on-Don, Russia \\ E-mail: annaivta@mail.ru
}




\section{Svetlana Valeryevna Gridneva}

Candidate of Psychology, Associate Professor

Southern Federal University

Rostov-on-Don, Russia

E-mail: gridneva-sveta@mail.ru

\section{Tat'iana Gavrilovna Stefanenko}

Doctor of Psychology, Professor

Moscow State University named after M. V. Lomonosov

Moscow, Russia

E-mail: tstef@yandex.ru

Olga Alekseevna Tikhomandritskaya

Candidate of Psychology, Associate Professor

Moscow State University named after M. V. Lomonosov

Moscow, Russia

E-mail: otihomandr@mail.ru

The paper brings forward results of the empirical study of the phenomenon of marriage satisfaction in bi-ethnic and mono-ethnic officially married couples. The authors distinguish the following main characteristics of marriage satisfaction: personal, mutual, average for a married couple, characteristics according to spheres of marriage (household, sexual-erotic, leisure, psychotherapeutic, birth and upbringing of children, unanimity of views and judgments of relatives and friends), features of conflicts in bi-ethnic and mono-ethnic marriages.

Methods of the study included (a) the analysis of the literature on the problem, (b) psycho-diagnostic method, (c) comparisons of respondent groups, and (d) methods of qualitative and quantitative and statistical analysis of the results.

Methodological tools included the "Marriage Satisfaction" test by O. O. Eremicheva and L. Ia. Gozman (in the adaptation of A. I. Tashcheva) and A. I. Tashcheva's questionnaire for studying basic socio-demographic, socio-economic and other 19 characteristics of married couples.

Partners of 30 officially married couples at the age from 25 to 35 (Russians, Armenians, Ossetians, Ukrainians, Belarusians, Georgians) took part in the empirical study.

From the results obtained in the present investigation the following conclusions were made. First, if to compare with bi-ethnic couples, mono-ethnic couples had reliably higher marital satisfaction in whole. Second, mono-ethnic couples had reliably higher scores in characteristics according to spheres of marriage (household, sexual-erotic, leisure, psychotherapeutic, birth and upbringing of children, unanimity of views and judgments of relatives and friends). 
The findings are of direct practical relevance and can be useful in psychological centers when working with marrying and divorcing couples with a different ethnic composition for the initial diagnostics of the quality of relationship in marriage, prevention and psychological correction of destructive marital conflicts to optimize the quality of marital relationship as a basic means of productive positive implementation of the state population policy.

This paper presents a part of a broader study entitled "Marital conflicts in bi- etnic couples at the age of early maturity" [7].

Keywords: marriage, matrimony, bi-ethnic marriage, mono-ethnic marriages, quality of marriage, criteria of marriage, marriage satisfaction, stability of marriage, broadened family, conflicts.

For citation: Tashcheva A. I., Gridneva S. V., Stefanenko T. G., Tikhomandritskaya O. A. Ethnically Mixed Marriages through the Phenomenon of Marriage Satisfaction. Russian Psychological Journal, 2016, V. 13, no. 3, pp. 39-52.

\section{Введение}

Удовлетворенность браком является одним из основных критериев качества и стабильности супружества, показателем потребности в профессиональной психологической помощи и степени готовности партнеров к получению таковой в случаях деструкции супружеских взаимоотношений $[1,4,10,12]$.

Особенно важен данный показатель в связи с глобальными изменениями в стране и сложной демографической ситуацией в ней. Так, по данным Росстата, ежегодно в современной России заключается около 250-300 тысяч браков и расторгается примерно половина из них. Из общего количества разводов $40 \%$ приходится на пары в возрасте ранней зрелости, фертильности (детородности). В Ростовской области показатели брачности и разводимости оказались еще более тревожными: с января по октябрь 2014 г. зарегистрировано 26129 браков и оформлено 15273 разводов, что составляет 58,45\% разводов от числа заключенных браков: на $17 \%$ больше, чем за аналогичный период прошлого года [6].

Не менее важным представляется и аспект значительного роста в России за последнее десятилетие тенденции увеличения доли разноэтнических браков: $15 \%$ от общего числа заключенных браков. На сегодняшний день примерно четверть населения Российской Федерации живет в многонациональных семьях, при этом растет количество смешанных браков с ближними этническими группами и уменьшается - с представителями далеких этнических групп [5, 8, 9].

Особенно много разноэтнических браков в многонациональных региональных образованиях. Например, в Ростовской области и г. Ростове-на-Дону 
только официальные биэтнические браки за последние два года составили $50 \%$ из общего числа зарегистрированных браков [6].

По мнению отечественных психологов, этнически смешанные (биэтнические, двуэтнические, разноэтнические) браки представляют собой особый вид супружества со сложной внутренней структурой, определяемой личностными особенностями супругов, принадлежавших к разным этническим группам, силой и устойчивостью их этнической идентификации, внешней глобальной межнациональной обстановкой в стране и в конкретном регионе, а также-внутренней микрокультурой брака, семьи.

Проблема межэтнических браков достаточно широко представлена в социологических (Ю. В. Арутюнян, 2005; Л. А. Делова, 2001; Л. М. Дробишева, 1971; А. Г. Здравомыслов, 1999; Н. Л. Крылова, 1995 и др.) и этнографических (О. А. Ганская, 1984; Ю. А. Евстигнеев, 1971; А. В. Козенко, 1978; А. Д. Коростелев, 2010; Я. С. Смирнова, 1967 и др.) научных работах, однако явно недостаточно эмпирических исследований психологических явлений в браке, в частности, - феномена удовлетворенности супружеством, важнейшего психологического критерия качества супружеских и семейных отношений, оказывающего максимальное влияние на развитие личности каждого из партнеров и их детей, а также членов их расширенной семьи $[1,2,3,4,5$, $10,12,13,14,15$ и др.].

Отечественные и зарубежные психологи выявили немало характеристик данного явления: связь удовлетворенности браком с наличием/отсутствием в семье детей, длительностью супружества, с удовлетворенностью каждого из супругов своей работой, с их ценностными ориентациями, с качеством добрачных отношений и т. д. Особенно плодотворными в этом плане были 90-е гг. XX в. и первое десятилетие XXI в., когда удовлетворенность как один из важнейших факторов качества супружества стала изучаться в своеобразных браках [1, 2, 3, 5, 6, 10, 11 и др.]. Результаты этих исследований достаточно полно описаны и хорошо известны, поэтому не будем на них останавливаться подробно.

Особую группу в этом ряду представляют исследования, в частности, удовлетворенности сексуальными отношениями партнеров, посвященные анализу механизмов вариативности формирования личностных сексуальных установок в возникновении представлений о норме и отклонениях, изучаемых в квир-теории в рамках гендерной дихотомии и репродуктивной функции (гомосексуальность, промискуитет, садомазохизм, трансвестизм и гермафродитизм и др.) безотносительно к браку, но, безусловно, имеющие отношение и к различным формам современного брака $[17,18,20,21,22]$ и т. д.

Продолжающаяся существенная трансформация современного российского общества, вызванная политическими, социальными и экономическими 
переменами, неизбежно вносит серьезные изменения и в институт семьи, требующий новых исследований.

Психологи свидетельствуют, что именно удовлетворенность браком является главным психологическим критерием качества супружеской и семейной жизни; оказывает максимальное влияние на развитие личности партнеров и их детей, следовательно, данное явление должно быть изучено именно психологами [1, 4, 10, 11, 13, 16, 19 и др.].

Практически не изучено явление удовлетворенности браком в двунациональных браках, что и определяет актуальность данной проблемы для современной России.

Цель данного исследования - изучение своеобразия удовлетворенности браком в биэтнических парах, по сравнению с парами однонациональными.

Предметом исследования данного фрагмента комплексной диагностики психологических характеристик двунациональных браков стали особенности удовлетворенности браком в биэтнических супружеских парах в возрасте ранней зрелости партнеров.

Эмпирический объект исследования-партнеры 30 официальных супружеских пар, каждому из которых 25-35 лет: русские, армяне, осетины, украинцы, белорусы, грузины. Все респонденты имеют среднее, среднее специальное или высшее образование; состоят в первом браке, на момент опроса бездетны, стаж их супружества составил 1-5 лет.

Выборка условно делилась на две равные группы по критерию национального состава супружеских пар: в основную группу вошли двуэтнические пары, в которых один из супругов (мужчина) был русским, второй-представителем одной из названных выше национальностей; в контрольную-пары однонационального состава - русские.

Основная гипотеза данного фрагмента исследования-национальный состав супружеской пары может быть связан с особенностями удовлетворенности браком каждого из партнеров и супружеской пары в целом.

Теоретической и методологической основой выступили системный подход в семейной психологии (М. Боуэн, С. Минухин, В. Сатир и др.); культурноисторический подход (Л. С. Выготский), исследования проблемы удовлетворенности браком (Ю. Е. Алёшина, Е. М. Дубовская, О. О. Ерёмичева, Л. Я. Гозман, О. А. Карабанова, А. И. Тащёва и др.), представления социологов (Ю. В. Арутюнян, Л. А. Делова, Л. М. Дробишева, А. Г. Здравомыслов, Н. Л. Крылова и др.) и этнографов (О. А. Ганская, Ю. А. Евстигнеев, А. В. Козенко, А. Д. Коростелев, Е. Е. Кутявина, С. К. Малышева, Я. С. Смирнова и др.) о межэтнических браках.

Методы исследования: анализ литературы по изучаемой проблеме, психодиагностический метод, метод сравнения групп, методы качественноколичественного и статистического анализа результатов. 
Методический инструментарий был представлен тестом «Удовлетворенность браком» О. О. Ерёмичевой и Л. Я. Гозмана и анкетой А. И. Тащёвой, выявляющей основные социально-демографические, социальноэкономические и иные 19 характеристик супружеских пар.

Статистическая обработка данных проводилась с использованием программы Statistica 10.0 методами описательной статистики, $\varphi$-критерия углового преобразования Фишера, критерия Шапиро-Уилка, параметрического t-критерия Стьюдента. Исследование осуществлялось в 2011-2016 гг.

\section{Процедура опроса}

Опрос каждого респондента осуществлялся лично, индивидуально, с добровольного согласия, и применительно к описываемому фрагменту исследования длился в среднем 40 минут. Диагностика осуществлялась в привычных для респондента условиях, у него на дому, в одну встречу.

Представим основные эмпирические результаты. Выявлено, что средний возраст супругов выборки однороден: в основной группе он составил $27,8 \pm 2,6$ лет, в контрольной группе $-28,9 \pm 2,9$ лет. Все респонденты состоят в бездетных браках. Обе группы однородны и по длительности супружества (2,3 $\pm 0,9$ и 2,2 $\pm 0,9$ соответственно). Одинаковым оказался и средний возраст вступления в брак в биэтнических парах: у мужчин $25,5 \pm 2,3$ лет, у женщин $-25,4 \pm 2,4$. В однонациональных же парах средний возраст вступления в брак у мужчин был несколько выше $(28,4 \pm 3,1)$, чем у женщин $(25,7 \pm 2,7)$.

Уровень дохода «выше среднего» был диагностирован в большинстве биэтнических пар и составил по выборке в целом $40 \%$, а в однонациональных парах в $30 \%$ случаев он характеризуется уровнями «выше среднего», «средним» и «ниже среднего». При этом в однонациональных парах чаще встречается уровень доходов «ниже среднего» (30\% случаев), а в биэтнических «низкий» фиксируется значительно реже (20\%).

В биэтнических парах зафиксирована среднегрупповая неудовлетворенность браком в $70 \%$ случаев, а удовлетворенность-в $30 \%$ случаев. В свою очередь, в однонациональных парах выявлена принципиально иная картина среднегрупповой удовлетворенности супружеством: $90 \%$ респондентов контрольной группы заявили, что они удовлетворены своим браком, и лишь $10 \%$ не удовлетворены им.

Личная удовлетворенность супружеством в биэтнических и в однонациональных парах составила в среднем соответственно 43,6 \pm 7,2 и 47,6 \pm 6,9 баллов при «нормативной» удовлетворенности от 34 баллов, что позволяет считать данный показатель по выборке в целом достаточно высоким.

Вместе с тем, в основной группе были обнаружены 50 \% пар с односторонней (один из супругов удовлетворен браком ниже среднего) или 
двухсторонней (у обоих партнеров этот показатель низкий) личной неудовлетворенностью; в контрольной группе подобная удовлетворенность оказалась свойственна лишь 40 \% пар. Данный показатель, по мнению А. И. Тащёвой, статистически достоверно свидетельствует о том, что разница между личной удовлетворенностью браком мужчины и женщины в супружеской паре, составившая 5,0 и более баллов, свидетельствует о факте высокой конфликтности в отношениях партнеров и отражает высокую вероятность нестабильности семейных отношений.

Важно и то, что в однонациональных парах $45 \%$ респондентов заявили о высокой личностной удовлетворенности супружеством, а в биэтнических парах эту характеристику удовлетворенности дали только $20 \%$ опрошенных.

Проведенный $\varphi$-критерий углового преобразования Фишера показал, что данная разница статистически значима ( $\varphi=1,72$, при $p=0,04)$.

В выборке в целом у $70 \%$ пар уровень взаимной удовлетворенности браком находится в пределах нормы, а у $30 \%$ пар наблюдается взаимная неудовлетворенность.

Рассмотрим удовлетворенность браком среди супругов двунациональных и однонациональных браков (таблица 1).

Таблица 1.

\section{Среднегрупповые значения удовлетворенности браком у супругов} двунациональных и однонациональных браков

\begin{tabular}{|c|c|c|c|c|}
\hline \multirow{2}{*}{ Переменные } & \multicolumn{2}{|c|}{ Биэтнические } & \multicolumn{2}{c|}{ Одноначиональные } \\
\cline { 2 - 5 } & $\boldsymbol{X}$ & $\boldsymbol{\sigma}$ & $\boldsymbol{X}$ & $\boldsymbol{\sigma}$ \\
\hline $\begin{array}{c}\text { Личная } \\
\text { удовлетворенность }\end{array}$ & 43,6 & 6,8 & 46,9 & 6,2 \\
\hline $\begin{array}{c}\text { Средняя удовлетво- } \\
\text { ренность на пару }\end{array}$ & 43,1 & 6,0 & 47,8 & 4,7 \\
\hline $\begin{array}{c}\text { Взаимная удовлетво- } \\
\text { ренность браком }\end{array}$ & $-1,3$ & 4,6 & $-2,4$ & 7,2 \\
\hline $\begin{array}{c}\text { Сексуально- } \\
\text { эротическая }\end{array}$ & 2,5 & 0,4 & 2,7 & 0,4 \\
\hline Рождение детей & 2,5 & 0,6 & 2,8 & 0,4 \\
\hline $\begin{array}{c}\text { Хозяйственно- } \\
\text { бытовая }\end{array}$ & 2,6 & 0,5 & 2,8 & 0,4 \\
\hline Досуговая & 2,5 & 0,5 & 2,8 & 0,4 \\
\hline $\begin{array}{c}\text { Единодушие } \\
\text { во взглядах, в оценке } \\
\text { родственников }\end{array}$ & 2,5 & 0,5 & 2,7 & 0,5 \\
\hline Психотерапевтическая & 2,6 & 0,5 & 2,8 & 0,4 \\
\hline \begin{tabular}{c} 
Воспитание детей \\
\hline
\end{tabular} & 2,4 & 0,5 & 2,5 & 0,6 \\
\hline
\end{tabular}


Как видно из таблицы 1, у партнеров, состоящих в двунациональных и однонациональных браках, выявлена средневыраженная удовлетворенность супружеством (43,6 \pm 6,8 и 45,9 46,2$)$, однако у супругов однонациональных пар личная удовлетворенность несколько выше. Также обнаружено, что у $37 \%$ супругов двунациональных пар и у $20 \%$ супругов однонациональных пар наблюдается неудовлетворенность, а у $33 \%$ супругов основной группы и у $53 \%$ супругов контрольной группы наблюдается достаточно высокая удовлетворенность браком.

Из таблицы 1 следует, что личная удовлетворенность браком соответствует средней удовлетворенности на пару, что указывает на наличие благополучных (стабильных) семей по критерию удовлетворенности в однонациональных супружеских союзах.

Вместе с тем, у респондентов основной группы было выявлено $43 \%$ случаев, а у супругов контрольной группы- 23 \% случаев несовпадения личной удовлетворенности и удовлетворенности браком на пару либо низкий уровень обоих показателей.

Взаимная же удовлетворенность браком в среднем находится в пределах нормы, что характерно для 53 \% партнеров из основной группы и у $67 \%$ супругов из контрольной группы; у остальных респондентов диагностирована заметная взаимная неудовлетворенность супружеством.

Анализ удовлетворенности каждой из сфер брака выявил, что удовлетворенность всеми сферами брака выше у супругов из однонациональных браков, по сравнению с супругами браков двунациональных.

Сравним степени «попарной» удовлетворенности браком супругов двунациональных и однонациональных супружеских пар (таблица 2).

Таблица 2.

Сравнение степени «попарной» удовлетворенности браком супругов двунациональных и однонациональных пар

\begin{tabular}{|c|c|c|c|c|}
\hline Переменные & $\begin{array}{c}\text { Среднее } \\
\text { (биэтнические) }\end{array}$ & $\begin{array}{c}\text { Среднее (одно- } \\
\text { национальные) }\end{array}$ & $\boldsymbol{t}$ & $\boldsymbol{p}$ \\
\hline $\begin{array}{c}\text { Личная } \\
\text { удовлетворенность }\end{array}$ & 43,6 & 46,9 & $-2,0$ & 0,054 \\
\hline $\begin{array}{c}\text { Средняя удовлет- } \\
\text { воренность браком } \\
\text { в паре }\end{array}$ & 43,1 & 47,8 & $-3,4^{* *}$ & 0,001 \\
\hline $\begin{array}{c}\text { Взаимная удовлетво- } \\
\text { ренность браком }\end{array}$ & $-1,3$ & $-2,4$ & 0,7 & 0,469 \\
\hline $\begin{array}{c}\text { Сексуально- } \\
\text { эротическая }\end{array}$ & 2,5 & 2,7 & $-2,2^{*}$ & 0,031 \\
\hline Рождение детей & 2,5 & 2,8 & $-2,1^{*}$ & 0,036 \\
\hline
\end{tabular}




\begin{tabular}{|c|c|c|c|c|}
\hline Переменные & $\begin{array}{c}\text { Среднее } \\
\text { (биэтнические) }\end{array}$ & $\begin{array}{c}\text { Среднее (одно- } \\
\text { национальные) }\end{array}$ & $\boldsymbol{t}$ & $\boldsymbol{p}$ \\
\hline $\begin{array}{c}\text { Хозяйственно- } \\
\text { бытовая }\end{array}$ & 2,6 & 2,8 & $-1,5$ & 0,143 \\
\hline Досуговая & 2,5 & 2,8 & $-2,6^{*}$ & 0,011 \\
\hline $\begin{array}{c}\text { Единодушие во взгля- } \\
\text { дах, в оценке } \\
\text { родственников }\end{array}$ & 2,5 & 2,7 & $-1,3$ & 0,198 \\
\hline Психотерапевтическая & 2,6 & 2,8 & $-1,5$ & 0,150 \\
\hline Воспитание детей & 2,4 & 2,5 & $-0,3$ & 0,770 \\
\hline
\end{tabular}

Примечание: * $-p<0,05 ;{ }^{*}-p<0,01$.

Из таблицы 2 следует, что между супружескими парами основной и контрольной групп существуют следующие значимые различия: по средней удовлетворенности браком ( $\mathrm{t}=-3,4$, при $\mathrm{p}=0,001)$, по сексуально-эротической сфере $(\mathrm{t}=-2,2$, при $\mathrm{p}=0,031)$, по сфере рождения детей $(\mathrm{t}=-2,1$, при $p=0,036)$ и по досуговой сфере $(t=-2,6$, при $p=0,011)$.

\section{Обсуждение результатов}

Таким образом, гипотеза исследования нашла свое качественно-количественное и статистическое подтверждение: для супругов однонациональных пар, по сравнению с бинациональными, характерны статистически достоверные более высокая удовлетворенность браком в целом и применительно к каждой из сфер супружества (хозяйственно-бытовая, сексуально-эротическая, досуговая, психотерапевтическая, рождение и воспитание детей, единодушие во взглядах и оценке родственников, друзей). Максимальной взаимная удовлетворенность диагностирована в сексуальных отношениях, в сферах воспитания детей и организации досуга.

Для проверки значимости выявленных различий был проведен параметрический t-критерий Стьюдента, т. к. с помощью критерия Шапиро-Уилка предварительно было доказано, что исследуемые переменные подчиняются закону нормального распределения.

Выявлено, что по уровню выраженности удовлетворенности браком существует значимое различие между биэтническими и однонациональными парами ( $\mathrm{t}=-2$, при $\mathrm{p}=0,04)$, при этом однонациональные пары характеризуются значимо более высокими показателями удовлетворенности супругов браком в отдельных сферах супружества, по сравнению с парами двунациональными. 


\section{Заключение}

Анализ содержания анкет респондентов, бесед с ними позволил предположить, что данные характеристики феномена удовлетворенности браком могут быть объяснены сходными, априорно, с раннего детства известными обоим партнерам национальными представлениями о супружестве, общностью взглядов каждого из них на роль мужчины и женщины в браке, на «уклад» семейной жизни, и детерминируемыми общими национальными и вероисповедальными традициями либо недостаточной осознанностью каких-то из названных характеристик факторов удовлетворенности браком у одного или же у обоих супругов, и пр.

Практическая значимость данного исследования заключается в возможности применения результатов в психологических центрах при работе с вступающими в брак и с разводящимися парами разного этнического состава для первичной диагностики качества взаимоотношений в браке, профилактики и психологической коррекции деструктивных супружеских конфликтов в них; а также для СМИ с целью повышения психологической культуры населения страны, Ростовской области в целях оптимизации качества супружеских отношений как одного из базовых средств продуктивной реализации государственной позитивной демографической политики.

\section{Литература}

1. Алешина Ю. Е. Удовлетворенность браком и межличностное восприятие в супружеских парах с различным стажем совместной жизни // Вестник МГУ. Серия 14. Психология. - 1987. - № 2. - С. 60-71.

2. Воронцов Д. В. Квир-теория: перспективы психологического анализа сексуальности // Вопросы психологии. - 2012. - № 2. - С. 153-162.

3. Гриднева С. В., Тащёва А. И. Оценка эффективности деятельности системы противодействия идеологии терроризма в молодежной среде // Российский психологический журнал. - 2013. - Т. 10. - № 5. - С. 23-31.

4. Карабанова О. А. Психология семейных отношений и основы семейного консультирования. - М.: Гардарики, 2008. - 320 с.

5. Кутявина E. Е., Малышева С. К. Разноэтническая семья как среда формирования этнической идентичности личности // Вестник Нижегородского университета им. Н. И. Лобачевского. Серия: Социальные науки. - 2010. - № 2. - С. 47-52.

6. Население Ростовской области // Федеральная служба государственной статистики. - URL: http://rostov.gks.ru

7. Проскурникова С. И. Супружеские конфликты в биэтнических парах в возрасте ранней зрелости: Выпускная квалификационная работа. Научный руководитель -А. И. Тащёва. - Ростов н/Д: Изд-во ЮФУ, 2016. - 99 с. 
8. Стефаненко Т. Г. Этнопсихология: Учебник для вузов. Изд. 5, испр. и доп. - М.: Аспект-Пресс, 2014. - 352 с.

9. Стефаненко Т. Г. Этнопсихология: Учебное пособие для вузов. - М.: Аспект-Пресс, 2013. - 224 с.

10. Тащёва А. И. Атрибутивные процессы в супружеских конфликтах: автореф. дисс. ... канд. психол. наук. - М., 1987. - 30 с.

11. Тащёва А. И., Киреева Л. Е. Ролевое поведение супругов «двухкарьерного» брака // Российский психологический журнал. - 2011. - Т. 8. № 4. - C. 44-55.

12. Тащёва А. И., Фрондзей С. Н. Личностные детерминанты особенностей супружеских конфликтов в неофициальном и официальном молодежных браках // Известия Южного федерального университета. Педагогические науки. - 2012. - № 1. - С. 118-126.

13. Тащёва А. И., Фрондзей С. Н. Неофициальные и официальные молодежные семьи // Вестник Адыгейского гос. ун-та. Серия Педагогика и Психология. - 2011. - № 1. - С. 157-165.

14. Тащёва А. И., Фрондзей С. Н. Особенности супружеских конфликтов в высоко удовлетворенных браком парах // Известия Южного федерального университета. Технические науки. - 2005. - № 7 (51). - С. 127-129.

15. Abakumova I. V., Yermakov P. N. On development of a tolerant personality in multicultural education // Questions of psychology. - 2003. - I. 3. pp. 78-82.

16. Afanasenko I. V., Tashcheva A. I., Gabdulina L. I. System of values of the youth in the light of its social frustration // The Social Sciences. - 2015. - 10 (6). pp. 1287-1290.

17. Connell R. W. Gender and Power: Society, the Person and Sexual Politics. Sydney: Allen \& Unwin, 1987.

18. de Lauretis T. "Habit Changes" // Differences: A Journal of Feminist Cultural Studies. - 1994. -V. 6. - pp. 296-313.

19. Gridneva S. V., Tashcheva A. I. Traditions of family mutual relations in the context of Beslan's terrorist attack // Virtual Presentation at the ICEEPSY International Conference on Education \& Educational Psychology. - Kyrenia, Cyprus: Elsevier Ltd. Procedia - Social and Behavioral Sciences, 2014.

20. Katz J. N. The Invention of Heterosexuality. - Chicago: The University of Chicago Press, 2007.

21. Queer Read This: A leaflet distributed at pride march in NY. Published anonymously by Queers //The Queer Resources Directory. - URL: http://www. qrd.org/qrd/misc/text/queers.read.this

22. Weeks J. The "homosexual role" after 30 years: An appreciation of the work of Mary Mclntosh // Sexualities. - 1998. -V. 1 (2). - pp. 131-152. 


\section{References}

1. Aleshina lu. E. Udovletvorennost' brakom i mezhlichnostnoe vospriiatie v supruzheskikh parakh s razlichnym stazhem sovmestnoi zhizni [Marriage satisfaction and interpersonal perception in married couples with various duration of their life together]. Vestnik MGU. Seriia 14. Psikhologiia-Bulletin of Moscow State University, Series 14. Psychology, 1987, no. 2, pp. 60-71.

2. Vorontsov D. V. Kvir-teoriia: perspektivy psikhologicheskogo analiza seksual'nosti [Queer theory: prospects of psychological analysis of sexuality]. Voprosy psikhologii - Approaches to Psychology, 2012, no. 2, pp. 153-162.

3. Gridneva S. V., Tashcheva A. I. Otsenka effektivnosti deiatel'nosti sistemy protivodeistviia ideologii terrorizma $v$ molodezhnoi srede [Estimating the efficiency of the system of counteraction to the ideology of terrorism in the youth environment]. Rossiiskii psikhologicheskii zhurnal - Russian Psychological Journal, 2013, V. 10, no. 5, pp. 23-31.

4. Karabanova O. A. Psikhologiia semeinykh otnoshenii i osnovy semeinogo konsul'tirovaniia [The psychology of family relations and fundamentals of family counseling]. Moscow, Gardariki Publ., 2008. 320 p.

5. Kutiavina E. E., Malysheva S. K. Raznoetnicheskaia sem'ia kak sreda formirovaniia etnicheskoi identichnosti lichnosti [Multi-ethnic families the environment for the formation of ethnic identity of the person]. Vestnik Nizhegorodskogo universiteta im. N. I. Lobachevskogo. Seriia: Sotsial'nye nauki - Bulletin of N. I. Lobachevsky State University of Nizhny Novgorod. Series: Social Sciences, 2010, no. 2, pp. 47-52.

6. The population of the Rostov region: Federal state statistics service. Available at: http://rostov.gks.ru

7. Proskurnikova S. I. Supruzheskie konflikty $v$ bietnicheskikh parakh v vozraste rannei zrelosti: Vypusknaia kvalifikatsionnaia rabota [Marital conflicts in biethnic couples at the age of early maturity: graduate qualification work]. Rostov-on-Don, Southern Federal University Publ., 2016. 99 p.

8. Stefanenko T. G. Etnopsikhologiia [Ethnopsychology]. Moscow, Aspekt-Press Publ., 2014. 352 p.

9. Stefanenko T. G. Etnopsikhologiia [Ethnopsychology]. Moscow, Aspekt-Press Publ., 2013. 224 p.

10. Tashcheva A. I. Atributivnye protsessy v supruzheskikh konfliktakh. Diss. kand. psikh. nauk [Attributive processes in marital conflicts. Cand. psych. sci. diss]. Moscow, 1987.

11. Tashcheva A. I., Kireeva L. E. Rolevoe povedenie suprugov «dvukhkar'ernogo» braka [Role behavior of spouses of a dual-career marriage]. Rossiiskii psikhologicheskii zhurnal - Russian Psychological Journal, 2011, V. 8, no. 4, pp. 44-55. 
12. Tashcheva A. I., Frondzei S. N. Lichnostnye determinanty osobennostei supruzheskikh konfliktov v neofitsial'nom i ofitsial'nom molodezhnykh brakakh [Personal determinants of characteristics of marital conflicts in informal and official marriages of young people]. Izvestiia luzhnogo federal'nogo universiteta. Pedagogicheskie nauki - Proceedings of Southern Federal University. Pedagogical Sciences, 2012, no. 1, pp. 118-126.

13. Tashcheva A. I., Frondzei S. N. Neofitsial'nye i ofitsial'nye molodezhnye sem'i [Informal and official youth families]. Vestnik Adygeiskogo gos. un-ta. Seriia Pedagogika i Psikhologiia - Bulletin of Adyghe State University. Series Pedagogy and Psychology, 2011, no. 1, pp. 157-165.

14. Tashcheva A. I., Frondzei S. N. Osobennosti supruzheskikh konfliktov v vysoko udovletvorennykh brakom parakh [Features of marital conflicts in couples with high marriage satisfaction]. Izvestiia luzhnogo federal'nogo universiteta. Tekhnicheskie nauki - Proceedings of Southern Federal University. Technical Sciences, 2005, no. 7 (51), pp. 127-129.

15. Abakumova I. V., Yermakov P. N. On development of a tolerant personality in multicultural education. Questions of psychology, 2003, I. 3, pp. 78-82.

16. Afanasenko I. V., Tashcheva A. I., Gabdulina L. I. System of values of the youth in the light of its social frustration. The Social Sciences, 2015, 10 (6), pp. 1287-1290.

17. Connell R. W. Gender and Power: Society, the Person and Sexual Politics. Sydney: Allen \& Unwin, 1987.

18. de Lauretis T. "Habit Changes". Differences: A Journal of Feminist Cultural Studies, 1994, V. 6, pp. 296-313.

19. Gridneva S. V., Tashcheva A. I. Traditions of family mutual relations in the context of Beslan's terrorist attack. Virtual Presentation at the ICEEPSY International Conference on Education \& Educational Psychology. Kyrenia, Cyprus: Elsevier Ltd. Procedia - Social and Behavioral Sciences, 2014.

20. Katz J. N. The Invention of Heterosexuality. Chicago: The University of Chicago Press, 2007.

21. Queer Read This: A leaflet distributed at pride march in NY. Published anonymously by Queers. The Queer Resources Directory. Available at: http:// www.qrd.org/qrd/misc/text/queers.read.this

22. Weeks J. The "homosexual role" after 30 years: An appreciation of the work of Mary McIntosh. Sexualities, 1998, V. 1 (2), pp. 131-152. 